\title{
LEVERAGING AN ENTERPRISE SOCIAL NETWORK FOR EMPLOYEE BEHAVIOR MODELING AND FORECASTING
}

\author{
Michael Stul, mstulphd@gmail.com \\ Conducive Corporation, Chicago, Illinois, USA
}

\begin{abstract}
The article evaluates the capabilities of an Enterprise Social Network to monitor and predict employee behaviors using an Enterprise social network. In recent years, Enterprise Social Networks, such as Microsoft's Yammer have become popular in the United States industry. As a rule, they are used as a platform for facilitating employee collaboration. The functionality of Enterprise Social Networks, however, supports their other, much broader, uses as drivers of change in organizational effectiveness. These uses include:

- Collecting and analyzing data on employee sentiment and behaviors. Establishing employee sentiment and behavior baselines

- Setting organizational effectiveness goals

- Creating organizational effectiveness metrics and setting targets

- Systematically monitoring organizational effectiveness goals against the targets and identifying gaps

- Creating and managing various programs for improving organizational effectiveness

- Supporting and sustaining organizations and groups, such as change networks

- Simulating desired behaviors in a controlled environment to establish, reinforce, and sustain the behaviors

- Modeling employee behaviors and sentiment

- Gauging short-term and long- term changes and trends in employee behaviors and sentiment over time to evaluate success of individual programs and organizational effectiveness in general

- Forecasting a change in employee behaviors and sentiment

- Reporting progress against set targets

These capabilities allow for successfully leveraging an Enterprise Social Network as a platform for the forecasting and modeling of employee behaviors. Target audiences for this article include Senior Leadership, members of the Project Management Organizations (PMO), Organizational Change Management Organizations (OCMO), the training teams, and organizational development consultants.

Keywords: social networks, social media, Microsoft Yammer, Enterprise, information, USA, Organizational Change Management, OCM, management, modeling, forecasting, employee, behavior, sentiment.
\end{abstract}

\section{Employee Behavior Modeling and Forecasting and Organizational Effectiveness}

The modeling and forecasting of employee behaviors is a part of organizational effectiveness planning. In the United States industry, organizational effectiveness planning is a part of the Business Planning process that entails setting goals for employee behaviors. Setting a goal for employee behaviors translates into creating a model of employee behaviors that would meet certain organizational effectiveness criteria thus allowing an organization to achieve its business goals.

Employee behavior modeling and forecasting is a subject of many studies. As part of their integrative model, Meyer, Becker, and Vandenberghe examined how such variables as 'goal choice, selfefficacy, and goal mechanisms' [1, p. 1004] impact employee behaviors. They also examined the role of employee commitment and goal regulations.

Brown, Willis, and Prussia's sociotechnical model studied the influence of both technical and social constructs on employee behavior (such as safe behaviors). 'These results demonstrate that safety hazards, safety culture, and production pressures can influence safety efficacy and cavalier attitudes, on a path leading to safe or unsafe work behaviors' [2, p. 445].

Griffin, Neal, and Parker created a model that 'extends understanding of the link between individual performance and effectiveness outcomes for organizations' [3, p. 343]. This research has defined work 
role behaviors in terms of organizational goals, thus 'identifying individual behaviors that lead to effectiveness in organizations' [3, p. 343].

Aquino, Lewis and Bradfield examined a relationship between employee perception of justice and deviant behaviors. The model 'showed that negative affectivity and interpersonal justice perceptions were directly related to... employee deviance' [4, p. 1087].

A study by Pierce, Rubenfeld, and Morgan [5] establishes a link between the formal ownership system and psychological ownership of a company by company employees. The importance of this study is in examining the mechanism by which a sentiment, a psychological sense of ownership is operationalized by employees.

Huang, Singh, and Ghose presented 'a dynamic structural model in which employees in an enterprise compete with each other in the process of reading and writing blog posts' [6, p. 32]. The importance of the study by Huang, Singh, and Ghose is that it establishes a link between employee behaviors of creating work-related and leisure-related content on an Enterprise social network. 'Our policy simulations suggest that prohibiting leisure-related posting will be counter-productive for organizations since it leads to a reduction in work-related posting too' [6, p. 33].

None of the studies, however, articulated the concept of an employee behaviors model by and of itself. The studies do not provide a definition of an employee behaviors model; neither do they describe the features of an employee behaviors model that would be conducive to the use in the industry. This definition is important as it provides employers, researchers, and practitioners with guidelines to study employee behaviors with respect to organizational effectiveness goals.

An employee behaviors model can be defined as a cluster or set of employee behaviors that are conducive to achieving an organizational effectiveness goal, thus supporting a company's business goals.

\section{What are the features of an employee behaviors model?}

First, this model is always specific as it is designed to support specific business goals. The achievement of company business goals calls for a workforce that exhibits certain behaviors that might not have been present upon an employee's hiring. These behaviors need to be developed, and companies do invest into identifying and developing these behaviors. The process of creating, testing, and implementing a business-goal specific employee behavior models is a part of organizational effectiveness planning.

An employee behavior model does not include every single behavior that an employee should demonstrate in the workplace. The foundation of organizational effectiveness planning is addressing the gaps between the current employee behaviors (that make employees unfit for their role and their inability to meet a company's business goals) and the behaviors that would ensure the workforce would address specific challenges that a company (or a division) faces. From that standpoint, organizational effectiveness planning is focusing on very specific behaviors, not every pattern in employee behavior. For example, if a company's 2017 business goal is to integrate multiple organizations across various subsidiaries into one cohesive organization with well-integrated processes, the organizational effectiveness part of the business plan should focus on identifying and supporting those initiatives ensuring an adequate communication between organizational roles that interact with each other as part of the integrated business process. Developing other employee behaviors may be out of scope for 2017 organizational effectiveness planning as they do not support that year's business goals. So, for a specific business planning period, a model of employee behaviors is not all-encompassing. That model is very specific and is addressing employee behaviors supporting this planning period's business goals.

Second, employee behaviors models are not a constant. They are only valid as long as they allow for resolving the gaps identified in specific employee behaviors. Rather, they tend to change from one business planning cycle to the next depending on specific business goals an organization (company, division) is setting out to achieve in a specific time range (one year, five years, over a longer time period). In any specific planning period, an employee behaviors model supports a finite number of organizational effectiveness goals and tends to change from planning period to planning period.

Let's say, in 2018, a company is planning on adopting a completely new management model and a business process that would enable that new management model. We are expecting large transformations in company culture, business processes, supporting applications, and personnel. To support 


\section{Управление в социально-экономических системах}

the business goal of enabling those changes and ensuring their success, the organizational effectiveness goal will be formulated as the need to nurture employee behaviors of malleability, flexibility, readiness for a change, thus improving the probability of adoption of the anticipated changes. Specific organizational effectiveness goals would translate into an understanding of which employee behaviors we would need to introduce, develop, enhance, nurture, and sustain or change/update over which period of time to ensure organizational effectiveness goals are met.

Third, an employee behaviors model is quantifiable. An employee behaviors model entails specific employee behaviors. Behaviors that comprise a model are easy to identify, document, and address (introduce, develop, enhance, sustain etc.) individually. When an organizational effectiveness goal changes, so does the employee behaviors model (in part or in its entirety). Organizational effectiveness goals are very specific and quantifiable. A behaviors model is just as quantifiable. For each of the employee behaviors that comprise a model, a metric can be defined. For example, improved communications across business functions across organizations can be quantified through such metrics, as the number of organizations involved in communications across business functions, the intensity of these communications, the frequency of such communications, the total number of employees in each organization engaged in these communications, the quality of the communications' content, the number of employees in each business function engaged in communications and so on. An employee behaviors model quantified through metrics can be easily evaluated (whether it fulfills its purpose of supporting the organizational effectiveness goals) and improved (by influencing individual behaviors that comprise the model). It is very important to monitor the intensity and trends in each of the behaviors that comprise a model over a period of time. The tracking and monitoring allow for experimenting with various interventions targeting the development of a specific employee behavior. It is equally important to forecast the changes in employee behaviors. A forecast will show how employee behaviors model will look like at a certain point in time in the future. These forecasts allow for proactively identifying risks (e.g., budgeting, scheduling) to the organizational effectiveness and overall business planning.

\section{What are the benefits of creating an employee behaviors model?}

First, companies create employee behavior models to set realistic employee behaviors goals that support organizational effectiveness planning. In the industry, a lack of understanding of employee behaviors and its drivers leads to a failure to create a realistic business plan. A typical business plan always includes an organizational effectiveness plan. Without an understanding of how employees will react to changes outlined in a business plan and how to drive their behaviors toward the desired business goals, company management will fail to establish metrics for defining and measuring overall business success. The lack of measurable targets will cause a company to miss the necessary activities to prepare employees for a successful execution of the plan. Without that, any business planning would be just an exercise in futility. Employee behaviors' modeling is, therefore, a vital part of business planning.

Second, employee behavior models are vital for the execution of a business plan. They allow for managing employee behaviors. Every business plan is formed based on the need to close performance gaps. Performance gaps are the reasons current performance has not reached the target levels outlined in metrics. Identifying gaps builds a foundation for creating and executing initiatives to close the gaps. No initiative, however, will ever be successful if company employees do not commit to executing business plans by participating in business initiatives. Unfortunately, some companies do not have a good understanding of employee behaviors and, therefore, underestimate the magnitude of their influence on the success of company initiatives. Employee behavior's modeling allows for the understanding and managing of the workforce. Without such an understanding, companies would constantly miss their targets in achieving their business goals because of the lack of employee support.

Managing employee behaviors will only be efficient when organizations responsible for managing those behaviors establish a practice and have the tools in place for forecasting, modeling, and influencing those behaviors. Regardless of their content, organizational effectiveness goals are only achievable if a company invests in these tools and processes.

\section{Why Enterprise social networks?}

Companies employ multiple strategies to improve organizational effectiveness. Leveraging Enterprise social networks is one of these strategies. Enterprise social networks, however, occupy a unique 
niche in creating, testing, and implementing an employee behaviors model. On the one hand, employing Enterprise social networks by and of itself is a method of managing employee behaviors, thus contributing to organizational effectiveness. On the other hand, Enterprise social networks provide a unique set of methods and tools for measuring, forecasting, and modeling a change in employee behaviors. Enterprise social networks have a broad range of instruments for assessing, documenting analyzing, modeling, and influencing behaviors which have resulted from implementing an Enterprise social network or other, non-social network-related, interventions.

What does employee behavior modeling and forecasting mean in reference to Enterprise social networks? In the case of an Enterprise social network (or any social network), we observe an activity of a social group (e.g., a group of employees). Forming, running, and participating in social groups is a cornerstone of a social network. As a general rule, there is a reason to hypothesize that the behaviors of a professional group on an Enterprise social network reflect the group's behaviors in the workplace outside of the virtual environment of an Enterprise social network. By studying an employee group's behaviors on an Enterprise social network we can document the most typical employee behaviors. When referencing employee behavior, the concept of a model allows us to:

- Document the current behaviors of employee groups ('Here is how employees behave now with respect to the major behavioral components that support the organizational effectiveness goals')

- Document the gaps between the desired employee behaviors (conducive to meeting the organizational effectiveness goals and aligned with the model of employee behaviors supporting these goals) and the currently demonstrated employee behaviors

- Observe and analyze the trends in the changes to employee behaviors over a period of time, thus supporting the forecasting of employee behaviors

- Forecast future behaviors based on the observable trends and the changes in employee behaviors. The forecasting allows for the prediction of the timing and the probability of closing the gap between the demonstrated employee behaviors in the observation period and the behaviors that support organizational effectiveness goals

- Leverage an Enterprise social network to introduce an intervention for the development of certain behaviors that comprise the employee behavior model supporting organizational effectiveness planning

These are the benefits of applying the concept of modeling to employee behaviors on an Enterprise social network. Simply stated, an Enterprise social network can provide data on how employee groups behave now and extrapolate the data on their future behaviors both on and outside of an Enterprise social network based on the observable and quantifiable trends.

\section{Microsoft's Yammer as an Enterprise Platform for Achieving Organizational Effectiveness}

We live in the age of Enterprise social networks. A company that decides to roll out an Enterprise social network to its employees will have many proven industry products to select from. That list includes Yammer, Tibbr, Jive, SocialCast, Convo, Kaltura, Chatter, Zyncro, SocialText, and Connections, to name just a few. Each product, however, serves its purpose and has its own niche in the Enterprise communications space. The common core of each Enterprise social network product is the ability to create employee communities. Social networks provide a centralized workplace and communication center for employees. Most Enterprise social networks provide a platform for group collaborative efforts around common tasks or project works. Some, such as Microsoft's Enterprise Social Network product called Yammer, provide a platform for supporting organizational effectiveness in a company. In this article, we are examining the practices for the forecasting and modeling of employee behaviors leveraging an Enterprise social network.

Our hypothesis for this research is that employee behaviors outside of Enterprise social networks can be influenced by systematically modeling, forecasting, and managing (using pertinent interventions) employee behaviors on an Enterprise social network. This research examines the methods and instruments for modeling and forecasting employee behaviors leveraging an Enterprise social network.

An Enterprise social network is in many respects an ideal space for verifying this hypothesis. First, an Enterprise social network is a sort of a virtual workplace whose purposes are to ensure employee communication and collaboration across employee groups and to support the flow of information between employees, management, and senior leadership. As compared to a non-virtual workplace, Enterprise social network makes it much easier to: 


\section{Управление в социально-экономических системах}

- Observe and document employee activities and interactions both within a group and across groups, as well as between employees and company management and leadership

- Evaluate and measure the level of these activities and interactions

- Track and measure the dynamics of these activities and interactions and observe how they change over time

- Forecast the future activities and interactions based on the past and current documented levels of these activities

- Immediately evaluate and measure the results of an intervention, both performed on the same Enterprise social network and outside of it, in a non-virtual workplace

There are, of course, many other instruments for collecting and analyzing this information. Specifically, surveys and observations are also common methods of data collection in the industry. The major difference between leveraging a survey and leveraging an Enterprise social network for collecting and evaluating data is that a survey uses employee self-evaluation making data somewhat less objective. It is also important to understand that even those employee responses that show support of the changes to company policies may not translate into the desired employee behaviors. This is especially true when a survey is conducted in the time of a change (e.g., policy changes due to a merger or acquisition). Employees may report their support of company policies in a survey. This support, however, might not mean that employee behaviors have changed appropriately and that employees follow the new policies systematically. In other words, self-reported support of the changes might not translate into the desired behaviors (actual support of the changes). This discrepancy might occur because of a variety of reasons. An evaluation of employee readiness for a change (employee behaviors that comprise a behaviors model that, in its turn, supports organizational effectiveness goals) must rely on objective metrics showing that employee behaviors have in fact changed and that employees continue to demonstrate the desired behaviors after these behaviors have been adopted over a designated time period.

Observing employee behaviors and evaluating a gap between the desired and the actual behaviors is the best way to evaluate whether the desired behaviors should stick. Conducting this evaluation outside of an Enterprise social network, however, is complicated and labor-intensive, therefore making this method less common in the current workplace. Observing multiple groups (ideally, all groups impacted by a change) at the same time over an extended period of time, as in a longitudinal study, is nearly impossible to facilitate due to the lack of specialized resources in a non-research-oriented business organization. Also, an observation, even an unobtrusive observation, tends to influence employee behaviors thus potentially biasing the results. An Enterprise social network is to a great extent an ideal instrument for collecting and analyzing data pertinent to employee and group interactions and other behaviors. This instrument is near perfect, as it entails employees creating content. Leveraging an Enterprise social network allows for studying artifacts resulting from employee and group activities over an extended period of time, unobtrusively, and with a great degree of accuracy.

For this analysis, we have chosen Microsoft's Yammer. Today, Microsoft's Yammer is a preferred platform in a company that is interested in promoting organizational effectiveness among its employees.

First, Yammer is, perhaps, the only tool whose User Interface is similar to Facebook, with status updates, picture-posting, praise, and follow capabilities. The familiar User Interface that Yammer features gives it a big advantage over other Enterprise social networks. Employees are more likely to use a platform as a reliable information source if they are not distracted or discouraged by a complicated and unfamiliar interface and controls. A near-zero need to spend time on the training of employees on Yammer is another big advantage. Everybody who ever used Facebook (and it's near impossible to find anyone in the US who has not) will instantly adopt Yammer and start using it. No training on the functionality is needed.

Second, Yammer is the only social network that supports reading human sentiment. When using Yammer, employees create posts. These posts express their feelings. Employee feelings can now be systematically analyzed using Yammer functionality called Crane. This functionality offers an insight into emotional trends demonstrated by employee groups within a company. The palette of emotions recognized by Yammer includes excitement, confusion and another 78 distinct emotions and feelings. Crane is capable of proving an analyst with a graph that shows how emotions in an employee group change over time. Yammer accomplishes this by recognizing the topics or words most often associated with these feelings. Human behaviors are influenced and driven by emotions, attitudes, beliefs, feelings, habits and 
so on. By managing these emotional and spiritual components as behavioral motivators, companies can efficiently manage employee behaviors that are both conducive to adopting a change and preventing rejection of a change. Companies which are interested in managing employee behaviors are very interested in systematically collecting and analyzing data about employee sentiment, both positive and negative, and the sources of sentiment-related information. Employers nowadays employ multiple ways to obtain employee feedback on various events occurring in the company. Obtaining and analyzing employee sentiment is a unique feedback that provides the training and communications professionals with an equally unique opportunity to develop a communications and training approach for driving employee behaviors in a desired direction.

Third, the training and communications professionals frequently employ change networks as an important channel to promote and support a change. A change network is a group of employees who are designated as Change Champions. Change Champions help promote a change in an organization. They help train other employees impacted by the change. They also help disseminate information and relay employee feedback to the appropriate managers. Typically, change champions are recruited among the most influential employees. Frequently, these influential employees are informal leaders. Sometimes, identifying and recruiting these influential informal leaders is a challenge. Yammer is capable of highlighting influential employees who can sway the sentiment that other employees express. Yammer is an important tool for identifying these influential informal leaders in an organization.

\section{Leveraging Enterprise Social Network Yammer}

This section addresses the practices companies may employ to leverage Yammer as an Enterprise social network for the modeling and forecasting of employee behaviors.

There are many ways to utilize Yammer in a company. In this article, the possible Yammer uses are reviewed in connection with the software functionality and the common industry practices for managing employee behaviors and improving organizational effectiveness.

These uses include:

- Collecting and analyzing data on employee sentiment and behaviors. Establishing employee behavior baselines

- Setting organizational effectiveness goals

- Creating organizational effectiveness metrics and setting targets

- Systematically monitoring organizational effectiveness goals against the targets and identifying gaps

- Modeling employee behaviors

- Gauging the short-term and long-term changes and trends in employee behaviors and sentiment over time to evaluate success of individual programs and organizational effectiveness in general

- Forecasting a change in employee behaviors

- Reporting progress against set targets

This article focuses on the methods for the modeling and forecasting of employee behaviors. Modeling, forecasting, or managing employee sentiment, as well as managing employee behaviors is out of scope for this article. Enterprise social networks are, in fact, capable of assessing, forecasting, modeling, and managing both employee sentiment and behaviors. We will address these areas in future research.

For illustration purposes, let's use a case of a fictitious company as an example. Organizational effectiveness entails addressing various challenges contributing to various aspects of employee behaviors. To simplify this illustration, however, this case study focuses on a specific challenge: employee communication practices as they are related to their business function.

\section{Case Study}

A large services company is experiencing a fast growth, primarily through mergers and acquisitions. In recent years, it has acquired several companies in the same industry, which now function as company subsidiaries. In 2016, Organizational Change Management Organization (OCMO) has conducted a survey to evaluate employee information sharing and communication practices within the company. The survey revealed that, as far as employee communication practices are concerned, the parent company and the company's subsidiaries operate in siloes. Communication between company employees and 


\section{Управление в социально-экономических системах}

their counterparts in the subsidiaries is limited, even between employees in the same functional area. The company's subsidiaries maintain their own unique business processes and procedures in each of the functional areas. Employees do not share information about best practices. This issue is exacerbated by employee sentiment, such as frustration, inertia, lack of trust in company management, and fatigue. A possible solution to this challenge is to improve communication among employees. The key challenge is that this behavior is not adopted by employees. These symptoms indicate low organizational effectiveness. The company's Senior Leadership has launched several initiatives to integrate business processes across the subsidiaries and with the parent organization. These initiatives, however, will take longer, perhaps a few years, to complete. The company owns an Enterprise license for Microsoft products, including Yammer, and Yammer has been rolled out to all company employees. Even though all users have access to Yammer, not all employees have ever accessed Yammer or participated in Yammer activities in any way. How can Yammer be leveraged to improve organizational effectiveness? Specifically, how can Yammer be leveraged to model and forecast employee behaviors as part of improving organizational effectiveness?

\section{Harvesting and analyzing data on employee behaviors}

First, let's define the challenge outlined in Case Study 2 by defining the current and desired employee behaviors. The desired behaviors will be in place when our intervention using Yammer Enterprise Social Network has completed successfully. Currently, company employees are not sharing information pertinent to their business function and business functions with which they interface, across organizations. The desired behavior is that sharing information pertinent to their business function and business functions with which they interface is a common behavior among company employees across various organizations.

Second, we need to identify employee behaviors that are conducive to the desired organizational effectiveness model. These behaviors are qualitative in nature and are described as follows:

- Employees create groups to share information pertinent to their functional areas and the functional areas with which they interface

- Employees join groups created to communicate information in their functional area and the areas they interface with

- Employees create content in their functional areas and the functional areas with which they interface

- Employees contribute/add content in their functional areas and the functional areas with which they interface with other employees across various company subsidiaries

- Employees actively consume the shared content in their functional areas and the functional and the functional areas with which they interface

- Some employees who create and consume content in their functional areas more actively than other employees are more popular than other employees (as judged based on the number of followers and shares each content item has acquired)

- Content in the targeted functional areas is followed and shared more actively than in other employee activity areas

Third, we need to set key quantitative metrics/targets to track whether the desired behaviors are adopted. The adoption of the desired behaviors indicates whether organizational effectiveness improves. These metrics are as follows:

- The number of active users (employees who participate in the groups that are engaged in sharing business-function-related information - target groups) increases

- The ratio of active users (employees who participate in the target groups) to total users (all employees who access Yammer, both active and inactive) increases

- The number of inactive users (users in the Yammer network who are not active in the target groups) decreases

- The number of public groups created with the purpose to share functional area-related information increases

- The number of public groups created with the purpose to share functional area-related information that fall into the top groups (the most popular groups) increases 
- Group activity in public groups created with the purpose to share functional area-related information increases. Group activity is evaluated based on the:

o Number of functional area-related items (original posts and messages and comments) posted by group members

$\circ$ Number of followers, likes, and shares each posted item has collected

- Content created by the target group members will become more popular than content created by members of other groups

Forth, we need to establish a measurable baseline to each of the current behaviors.

Example: Currently, $23 \%$ of all employees are among active users (employees who participate in groups which are engaged in sharing business-function-related information).

Finally, we need to assign a desired quantitative target rate to each of the metrics.

Example: The number of active users (employees who participate in groups which are engaged in sharing business-function-related information) increases by $25 \%$ over a one-year period as compared to the baseline and will reach $48 \%$ of all employees by December 31, 2017.

\section{Yammer functionality ${ }^{1}$ supporting the modeling and forecasting of employee behaviors}

Yammer supports the modeling and forecasting of employee behaviors. Harvesting and analyzing data provided in Yammer reports allows for reviewing the dynamics of the metrics aligned with the targeted employee behaviors. The following Yammer reports are highlighted to illustrate data harvesting and analysis pertinent to the specific business challenge outlined in the case study. Obviously Yammer has much broader Business Intelligence capabilities and includes such reports as Messages Posted, and Content Contribution reports. They can be leveraged for data harvesting for some other employee behavior models. They are, however, out of scope for this article.

Fig. 1 show a report on the dynamics of the total number of users and public and private groups over a period of time (on a daily basis, over a one-month period).

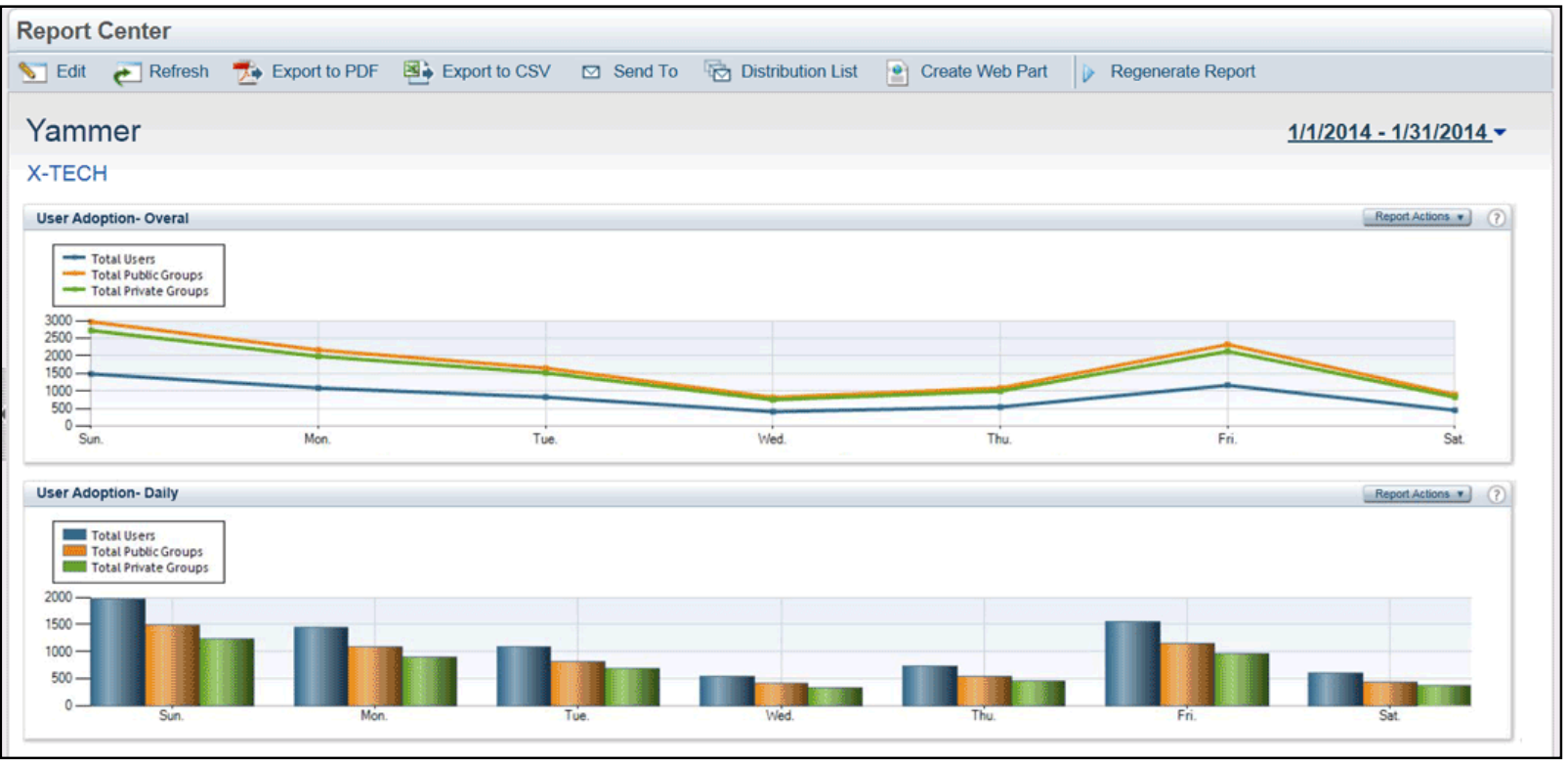

Fig. 1. User Adoption

The User Adoption report shows the dynamics in the total number of users and in public and private groups. This mockup data show how the total number of active users changes on a daily basis over a time range. This report allows for reviewing the changes to the total number of users as well as to the number of users in public groups (the groups involved in business-related activities across various busi-

${ }^{1}$ All discussions to Yammer functionality / reports are referencing screenshots provided by CardioLog Analytics (http://www.intlock.com/products/screen-shots/). 


\section{Управление в социально-экономических системах}

ness functions) as well as to the number of users in private groups (the groups which may have been created for discussing extracurricular activities).

This report does not provide specific information on the purpose of public groups. Some public groups may be created for other purposes. This limitation of Yammer functionality, however, can be mitigated by implementing a process by which all public groups are created for generating and sharing the content relevant to the target employee behaviors. Employees will still have an option of creating a group in Yammer, but those groups will only be private.

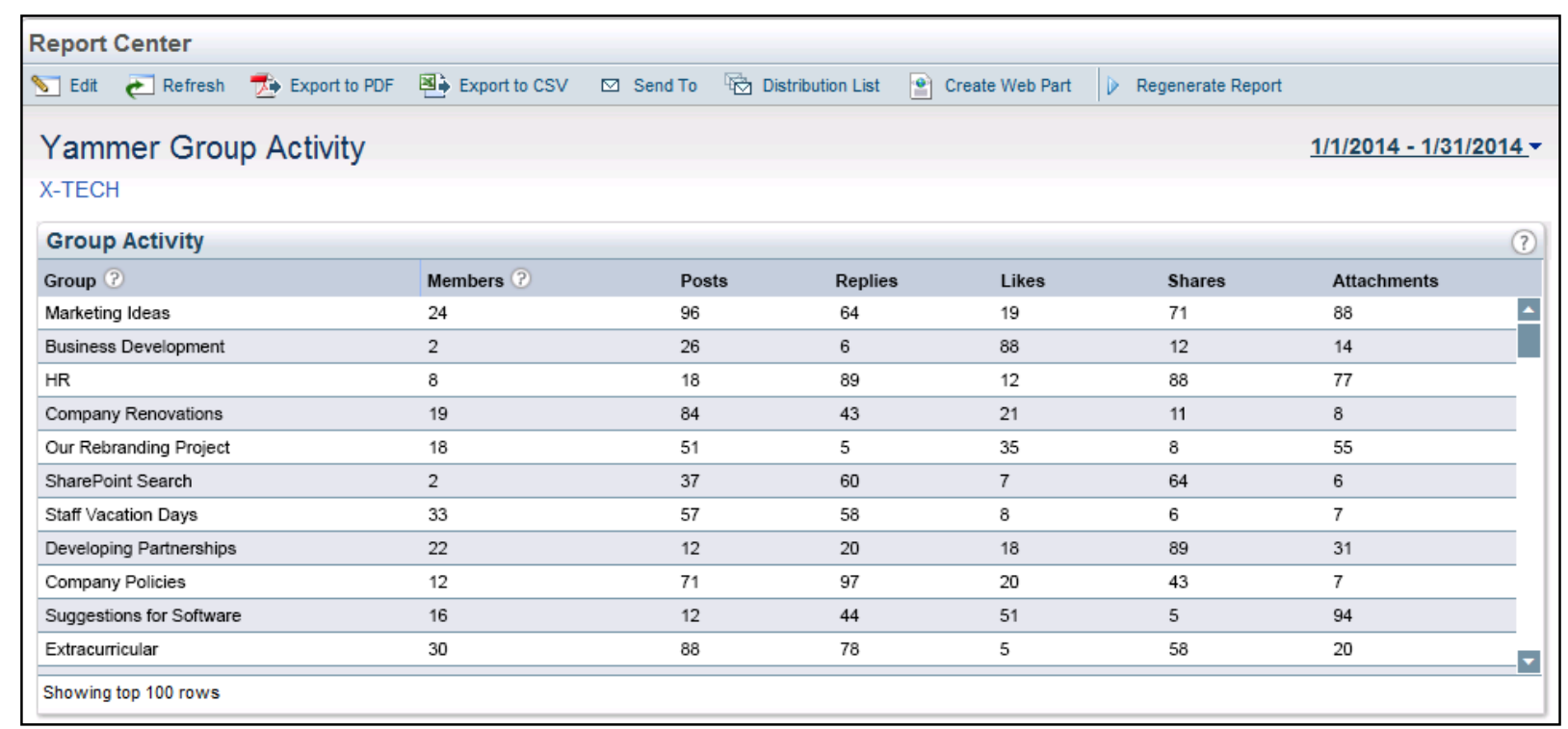

Fig. 2. Group Activity

The Group Activity report is instrumental for monitoring a growth in group membership (Fig. 2). It shows the number of members in each group over a designated period of time. It also breaks down member activities by category, including original posts (posting the original content on Yammer), replies, likes, and shares of the original posts for each group. This report allows for identifying the trends in member activities depending on a group's purpose. It is instrumental when demonstrating the trends in communication activity across various business functions or the trends in communication activities that discuss specific events and changes (e.g., a CIO's town hall or new company policies).

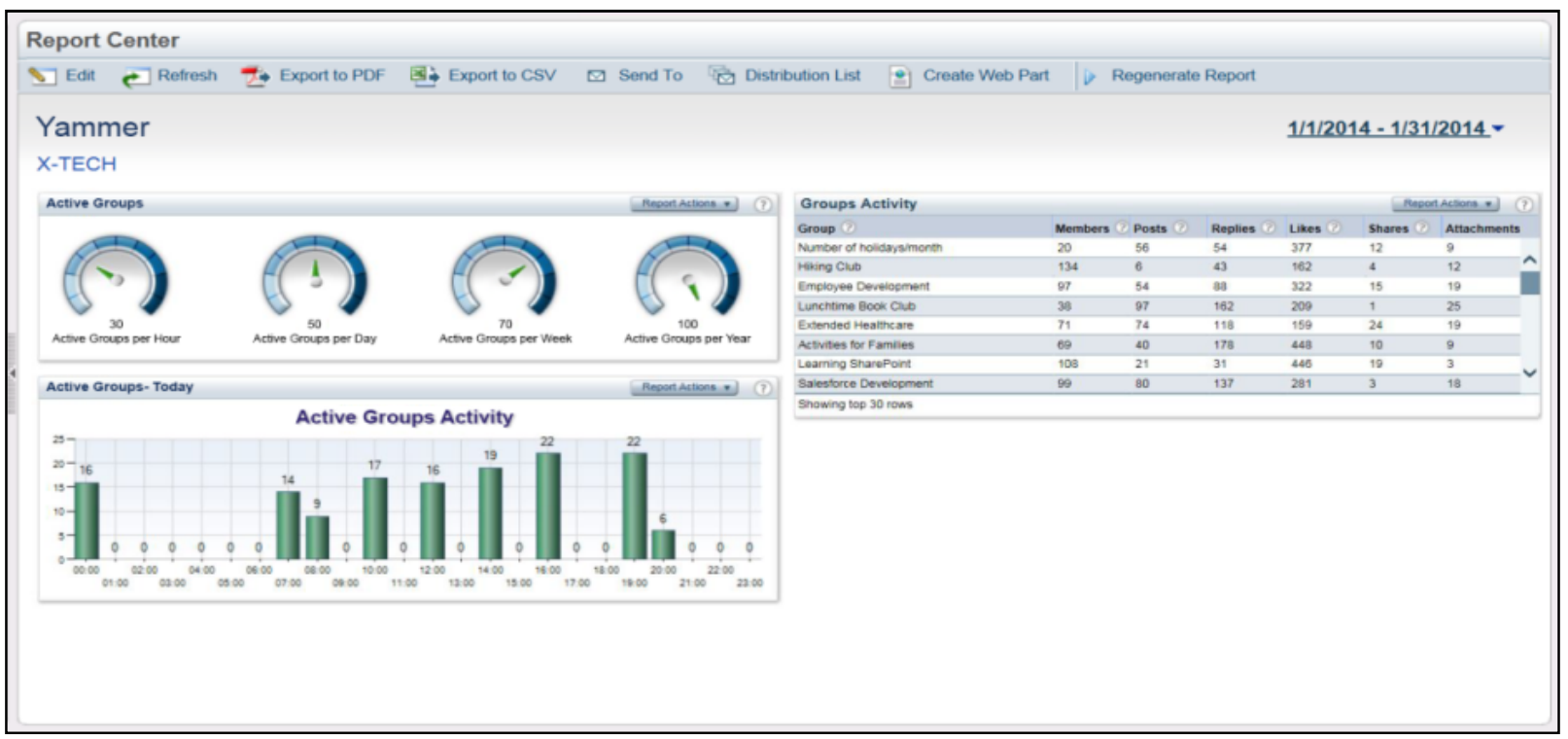

Fig. 3. Top Groups and Active Groups reports 
The Top Groups and Active Groups reports are instrumental for collecting data on a content that contributes to a group's popularity (Fig. 3). The most popular groups ('top groups') are those groups that receive the most membership requests. By tracking the top groups, we can track popularity a specific content (e.g., functional area-related) and analyze whether that content is what makes a group popular. Furthermore, this report allows for analyzing the dynamics of the top groups' popularity over a time range. This feature provides data on the trends of the desired activities with respect to a s specific content. Another feature of this report allows for establishing a relationship between the top groups' activity and a time of day these activities occur the most. This data is instrumental for the planning of communication and engagement interventions, such as targeted emails, meetings with change champions, and sharing information with work groups by Senior Leadership and management. This is where employee activities on an Enterprise social network help support and improve efficiency of other activities that occur outside of a social network. Also, this report can help track the efficiency of interventions to manage employee behaviors as it can show a relationship between an intervention and the intensity and frequency of group activities.

Data harvested from these reports can be augmented with data collected from the Active Groups and report. The analysis of this data provides an insight on the dynamics of active groups (groups whose members create content aligned with the tracked behaviors). This report help provide data to support an analysis on whether the number of active groups engaged in creating certain content will grow when employees are provided with an environment to share content (e.g., related to their functional areas) with other employees across the Enterprise.

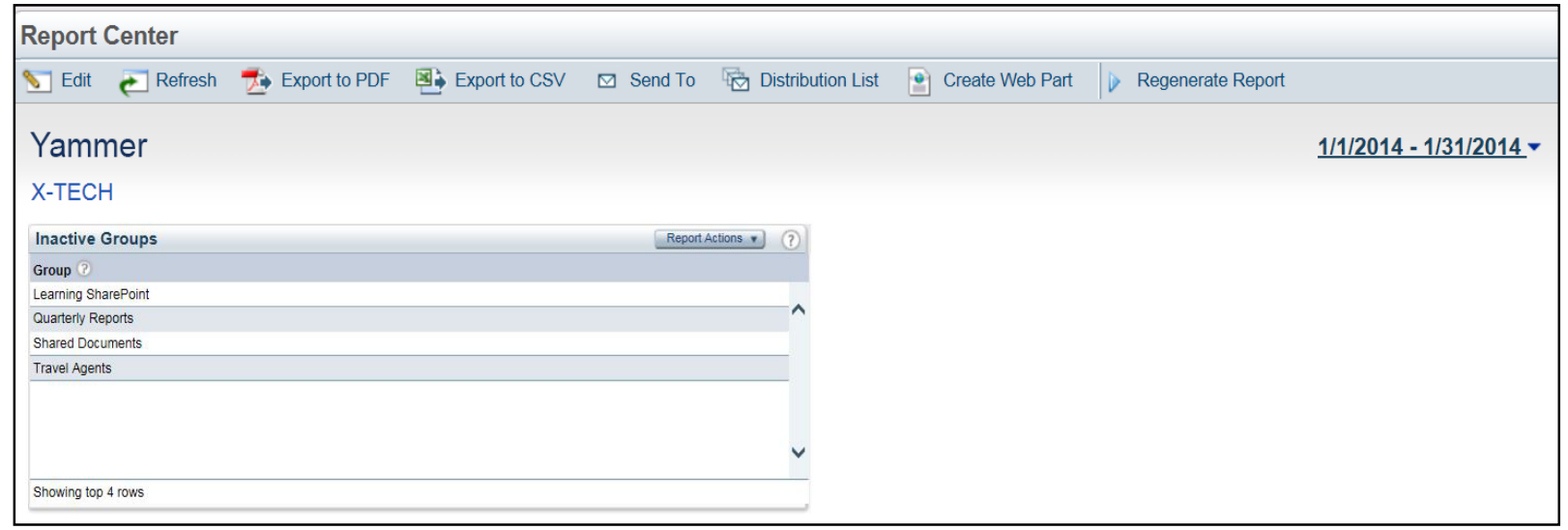

Fig. 4. Inactive Groups

Data harvested from the Active Groups report can be augmented with the data harvested from the Inactive Groups report. The Inactive Groups report provides data on groups whose members have registered a group, but create no content (Fig. 4). Data harvested from this report can also support a research on the content aligned with the tracked behaviors (e.g., creating and sharing data in their functional areas with other employees). In our study, the report will show that those groups that create the desired content will continue to stay active (and never reflect on the Inactive Groups report). On the other hand, this report can show whether the desired employee behaviors are stable or requires sustainment (in the case of the groups supporting these behaviors ending up on the Inactive Groups report over a certain time range).

User reports (Active Users, Inactive Users, and Total Users) can be reviewed to gauge employee engagement in the overall communications process (Fig. 5-7). Using these reports to address the target employee behavior with respect to creating a specific content requires extra drilling down. The reports are instrumental for analyzing the trends in active/inactive/total user ratios. These trends provide indirect data on specific employee behavioral patterns, but do contribute to the painting of the broader employee activity picture in the company. 


\section{Управление в социально-экономических системах}

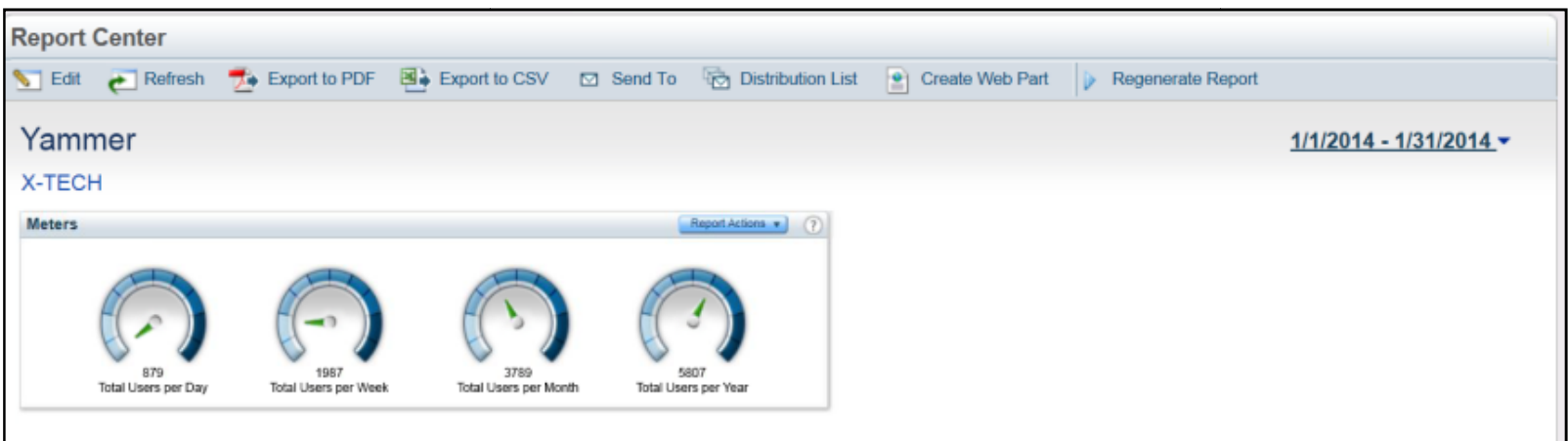

Fig. 5. Active Users

\begin{tabular}{|ll|}
\hline $\begin{array}{l}\text { Inactive Users } \\
\text { User } 8\end{array}$ & Search: \\
\hline Ava Reynolds & Content Contributions \\
\hline Braden Carrington & Content Modifications \\
\hline Braden Gissing & Default User Template \\
\hline Braden Jacobson & Followers \\
\hline Craig Catt & Praised By \\
\hline Craig Johnson & Search \\
\hline Previous 112 Next & Sitrion Colleagues \\
& Users Template \\
& Visitor Overview \\
& Visitor Profile \\
& Copy to Clipboard \\
\hline
\end{tabular}

Fig. 6. Inactive Users

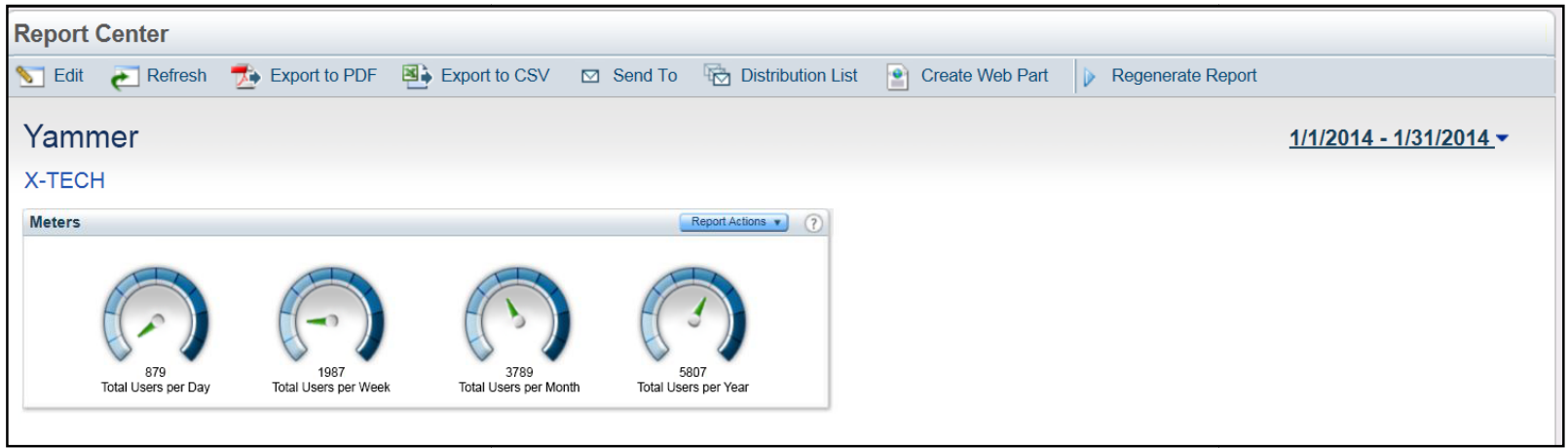

Fig. 7. Total Users

The Influential Content report shows the discussion topics that have the largest number of followers and are shared the most by employees (Fig. 8). Data harvested from this report can show employee interest in the targeted behaviors. The content shared the most and the one having the most followers will indicate whether the targeted employee behaviors are becoming popular among company employees. In other words, this report will show the rate of adoption of the targeted behaviors among company employees. The most popular content (e.g., with respect to a specific business function) indicates the higher rate of adoption of the desired behaviors among employees (e.g., sharing business-function-related information with other employees). This report can also show the dynamics in popularity of the target behaviors over a time range. By analyzing the popularity trends of the targeted content we can harvest data on the targeted behavior adoption. We can also forecast the adoption rate for the targeted behaviors and whether the desired employee behavior model will be adopted by the target date. 


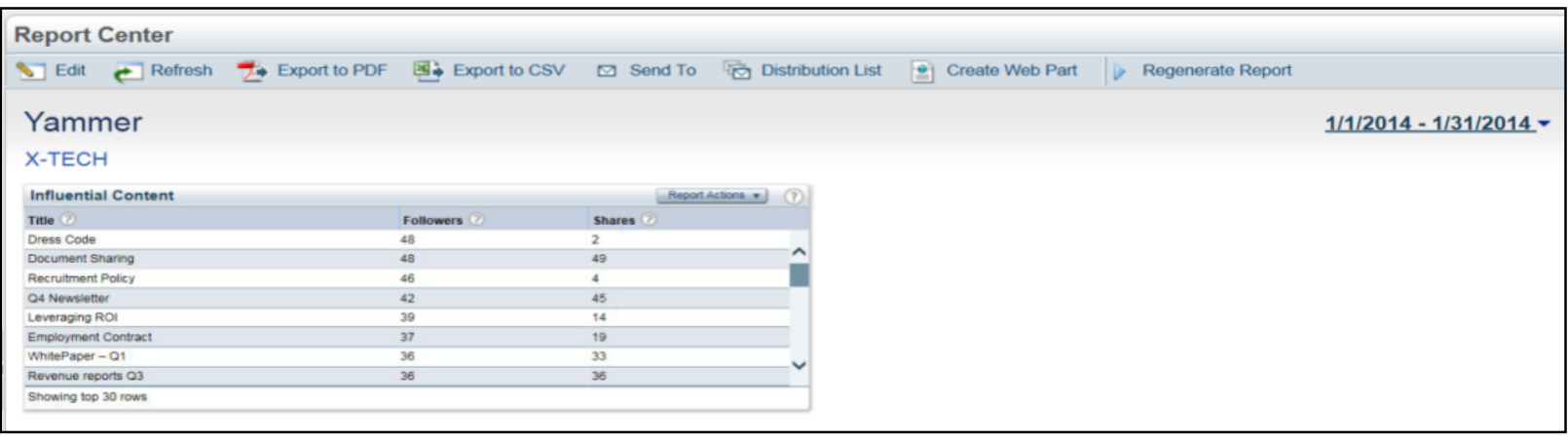

Fig. 8. Influential Content

Table 1 summarizes the type of data that can be harvested to analyze the dynamics of the metrics, aligned with the targeted employee behaviors.

Data harvested, per Yammer report

Table 1

\begin{tabular}{|c|c|c|}
\hline$\#$ & Report Title & Description of Data Harvested \\
\hline 1 & User Adoption Rate & $\begin{array}{l}\text { - The number of users registered on Yammer and the number of } \\
\text { groups (both private and public) } \\
\text { - The dynamics of change in the number of registered users and } \\
\text { groups }\end{array}$ \\
\hline 2 & Groups Activity & $\begin{array}{l}\text { - Most and least active groups in organizations and across the Enter- } \\
\text { prise } \\
\text { - Group members might need extra support regarding specific topics, } \\
\text { content and activities }\end{array}$ \\
\hline 3 & Top Groups & $\begin{array}{l}\text { - Most popular groups (groups that discuss topics that are of interest to } \\
\text { the largest number of Yammer users in the organizations) } \\
\text { - Groups with most membership requests }\end{array}$ \\
\hline 4 & Active Groups & $\begin{array}{l}\text { Groups whose members add most content (posts, replies, likes, shares, } \\
\text { and attachments) }\end{array}$ \\
\hline 5 & Inactive Groups & $\begin{array}{l}\text { Groups that have been set up but whose members are not using Yam- } \\
\text { mer to create content }\end{array}$ \\
\hline 6 & Active Users & $\begin{array}{l}\text { - The number of active users creating content per time range (day, } \\
\text { week, month, year) } \\
\text { - The number of active users creating content per time range within } \\
\text { a day (e.g., from } 1 \text { until } 2 \text { pm ET). }\end{array}$ \\
\hline 7 & Inactive Users & $\begin{array}{l}\text { Number of users who have registered, set up their accounts, but do not } \\
\text { create content }\end{array}$ \\
\hline 8 & Total Users & Total number of users registered in Yammer \\
\hline 9 & Influential Content & $\begin{array}{l}\text { - Content that has most likes and shares indicating a feedback from } \\
\text { users (interest, usage, and appeal) per content type } \\
\text { - Number of followers and shares of specific content }\end{array}$ \\
\hline
\end{tabular}

By leveraging Yammer reports for harvesting data and analyzing the data, we can:

- Systematically collect data pertaining to employee behaviors aligned with the current and desired employee behavior model

- Systematically compile data indicating the current state of the behaviors pertinent to the model of employee

- Track the dynamics of each metric contributing to employee behavior model

- Forecast the future state in the metrics aligned with employee behaviors over a target time period (e.g., over a six-or 12-months period) based on the trends showing in the metrics 


\section{Управление в социально-экономических системах}

- Forecast the changes in the employee behavior model over a target time range. For example, we can forecast whether employees will become more collaborative and start sharing content within their business functions with their group members and members of other groups across the Enterprise by a target future date

\section{Conclusion}

Organizational effectiveness planning is a part of the business planning process. The modeling and forecasting of employee behaviors and sentiment are important conditions for organizational effectiveness planning. This article focuses on employee behaviors and leaves employee sentiment out of scope. By creating a model of employee behaviors, we define behaviors conducive to meeting organizational effectiveness goals. The forecasting of employee behaviors is important for facilitating various interventions that make the achievement of organizational effectiveness goals possible.

Enterprise social networks provide a perfect environment for contributing to the modeling, forecasting, and ultimately managing employee behaviors. They provide instruments for creating a baseline of employee behaviors, helping define the desired behaviors (thus supporting employee behaviors modeling and making it possible), and supporting the tracking of employee behaviors (thus supporting the forecasting of employee behaviors). Enterprise social networks also provide the instruments for creating an environment conducive to meeting organizational effectiveness goals. Using Yammer, an Enterprise social network by Microsoft as an example, this article demonstrated the instruments that support the modeling and forecasting of employee behaviors. These Business Intelligence (BI) instruments allow for data harvesting, data analysis, and the forecasting of employee behaviors captured in the key metrics. These instruments are available as part of Microsoft Power BI (Business Analytics) functionality and Yammer analytics. Additional analytical instruments, such as CardioLog Analytics, are available from suppliers, such as Interlock.

\section{Future Research}

I see several potential directions in which we can take this research. First, Enterprise social networks, such as Yammer, are powerful tools for assessing, forecasting, modeling, and managing employee sentiment. Future research will focus on examining methods and tools Yammer employs to support collecting and analyzing data on employee sentiment, forecasting and modeling that sentiment, and influencing it.

Second, future research will focus on aspects of employee behaviors other than employee communication and information sharing. Organizational effectiveness is a complex concept. Depending on company goals, employee behaviors that comprise that concept may include such behaviors as employee creativity, adaptability to a change, succession planning, developing employee leadership etc. Future research may focus on examining the role of an Enterprise social network in creating the desired behaviors in these areas of organizational effectiveness.

Third, in future research, we will demonstrate a relationship between employee behaviors on an Enterprise social network and their behaviors outside of this network. The current study has a limitation. It makes an assumption about a relationship between employee behaviors on Enterprise social networks and their relevant behaviors outside such networks. This study, however, does not demonstrate this relationship. The future study will demonstrate a relationship between employee behaviors on Enterprise social networks and outside of such networks in the modern workplace. The future study is important for the understanding of how employee behaviors model can be leveraged to manage employee behaviors that occur outside of an Enterprise social network.

\section{References}

1. Meyer J.P., Becker T.E., Vandenberghe C. Employee Commitment and Motivation: A Conceptual Analysis and Integrative Model. Journal of Applied Psychology, Dec. 2004, vol. 89(6), pp. 991-1007. DOI: 10.1037/0021-9010.89.6.991

2. Brown K.A., Willis G.P., Prussia G.E. Predicting Safe Employee Behavior in the Steel Industry: Development and Test of a Sociotechnical Model. Journal of Operations Management, June 2000, vol. 18, issue 4, pp. 445-465. DOI: 10.1016/S0272-6963(00)00033-4 
3. Griffin M.A., Neal A., Parker S. K. A New Model of Work Role Performance: Positive Behavior in Uncertain and Interdependent Contexts. Academy of Management Journal, April 1, 2007, vol. 50, issue 2, pp. 327-347. DOI: 10.5465/AMJ.2007.24634438

4. Aquino K, Lewis M.U., Bradfield M. Justice Constructs, Negative Affectivity, and Employee Deviance: A Proposed Model and Empirical Test. Journal of Organizational Behavior, Dec. 1999, vol. 20, issue 7, pp. 1073-1091. DOI: 10.1002/(SICI)1099-1379(199912)20:7<1073::AID-JOB943>3.0.CO;2-7

5. Pierce J.L., Rubenfeld S.A., Morgan S. Employee Ownership: A Conceptual Model of Process and Effects. Academy of Management Review, January 1991, vol. 16, issue 1, pp. 121-144. DOI: 10.2307/258609, DOI: 10.5465/AMR.1991.4279000

6. Huang Y., Singh P.V., Ghose A.A Structural Model of Employee Behavioral Dynamics in Enterprise Social Media. Management Science, May 2015, vol. 61, issue 12, pp. 2825-2844. DOI: $10.1287 / \mathrm{mnsc} .2014 .2125$

Received 29 August 2017

\title{
ИСПОЛЬЗОВАНИЕ ВОЗМОЖНОСТЕЙ КОРПОРАТИВНОЙ СОЦИАЛЬНОЙ СЕТИ ДЛЯ МОДЕЛИРОВАНИЯ И ПРОГНОЗИРОВАНИЯ ПОВЕДЕНИЯ СОТРУДНИКОВ
}

\author{
М. Стуль \\ Conducive Corporation, Чикаго, uтат Иллинойс, США
}

\begin{abstract}
Оцениваются возможности корпоративных социальных сетей как средства управления поведением сотрудников предприятия или организации. Корпоративные социальные сети, такие, например, как Яммер от компании Майкрософт, очень популярны на предприятиях и в организациях в США. Как правило, корпоративные социальные сети используются в качестве платформы, обеспечивающей обмен сообщениями между сотрудниками, занятыми на одном проекте или работающими в одной организации. Однако возможности корпоративных социальных сетей гораздо шире.

Практика перспективного и ежегодного планирования бизнеса в США предусматривает создание планов повышения эффективности организаций и путей реализации этих планов. В США термины «организационная эффективность» или «эффективность организаций» описывают раздел перспективного планирования, связанный с развитием персонала предприятия или организации. Целью повышения эффективности организаций является создание и закрепление определенных норм поведения персонала, способствующих достижению организацией поставленных целей. В статье описана практика применения корпоративных социальных сетей:

- для сбора, обработки и анализа данных об эмоциях и поведении сотрудников;

- постановки целей и задач организации в области организационной эффективности;

- систематического отслеживания темпов реализации поставленных задач в этой области;

- создания разнообразных программ, способствующих улучшению организационной эффективности, и управления этими программами;

- отслеживания тенденций изменения поведения сотрудников в кратко и долгосрочной перспективе с целью оценки эффективности таких программ;

- создания и поддержки неформальных рабочих коллективов и групп, способствующих внедрению норм поведения и инноваций;

- создания условий для апробации моделей желаемого поведения сотрудников;

• моделирования желаемого поведения и эмоционального настроя сотрудников;

- прогнозирования изменений в поведении и эмоциональном настрое сотрудников;

- автоматизации отчетов организации о результативности;

• создания и закрепления определенных норм поведения персонала.
\end{abstract}




\section{Управление в социально-экономических системах}

Корпоративные социальные сети дают широкие возможности для прогнозирования, моделирования и управления поведением и эмоциональным состоянием сотрудников. В статье описывается практика использования корпоративных социальных сетей для решения этих задач и приводится описание инструментов для сбора данных и отслеживания тенденций поведения сотрудников. Целевая аудитория статьи - руководители предприятий и организаций, специалисты по управлению проектами, организационной динамике и тренировке персонала.

Ключевые слова: сочиальные сети, медиа, Яммер, корпоративный, информачия, США, управление внедрением инновачий, моделирование, прогнозирование, поведение сотрудников, эмоциональное состояние.

Стуль Михаил, PhD, директор Учебных программ, Conducive Corp., Чикаго, штат Иллинойс, СШA; mstulphd@gmail.com.

Поступила в редакцию 29 августа 2017 г.

\section{ОБРАЗЕЦ ЦИТИРОВАНИЯ}

Stul, M. Leveraging an Enterprise Social Network for Employee Behavior Modeling and Forecasting / M. Stul // Вестник ЮУрГУ. Серия «Компьютерные технологии, управление, радиоэлектроника». - 2017. T. 17, № 4. - C. 98-112. DOI: 10.14529/ctcr170411

\section{FOR CITATION}

Stul M. Leveraging an Enterprise Social Network for Employee Behavior Modeling and Forecasting. Bulletin of the South Ural State University. Ser. Computer Technologies, Automatic Control, Radio Electronics, 2017, vol. 17, no. 4, pp. 98-112. DOI: 10.14529/ctcr170411 